Am J Ophthalmol. 2015 March ; 159(3): 470-474. doi:10.1016/j.ajo.2014.11.028.

\title{
The Association Between Dry Eye Disease and Depression and Anxiety in a Large Population-Based Study
}

\author{
Robert van der Vaart, M.D., \\ The University of North Carolina at Chapel Hill, Department of Ophthalmology, \\ rvanderv@unch.unc.edu
}

\section{Mark A. Weaver,}

The University of North Carolina at Chapel Hill School of Medicine, Mark_weaver@med.unc.edu

Chelsea Lefebvre, M.D., and

The University of North Carolina at Chapel Hill, Department of Ophthalmology, cgcastellano@gmail.com

\section{Richard Marc Davis, M.D.}

The University of North Carolina at Chapel Hill, Department of Ophthalmology, 5151

Bioinformatics Building, Campus Box 7040, Chapel Hill, NC 27599-7040,

Richard_davis@med.unc.edu, 919.966.5296 (phone), 919.966.1908 (fax)

\section{Abstract \\ Purpose-To investigate the association between dry eye disease and each of depression and anxiety.}

Design-Retrospective, case-control study

Setting: University of North Carolina outpatient clinics

Study Population: All patients over the age of 18 years old seen between July of 2008 and June of 2013 were included in the analysis.

Observation Procedure: Cases were defined according to ICD-9 diagnosis codes for dry eye disease, anxiety, and depression.

Outcome Measure: Separate odds ratios were calculated for dry eye disease and each of anxiety and depression. Similar odds ratios were also calculated between dry eye disease and rheumatoid arthritis, a systemic disease with a known association with dry eye, as a way of validating our approach.

\footnotetext{
(C) 2014 Elsevier Inc. All rights reserved.

Correspondence to: Richard Marc Davis.
}

Publisher's Disclaimer: This is a PDF file of an unedited manuscript that has been accepted for publication. As a service to our customers we are providing this early version of the manuscript. The manuscript will undergo copyediting, typesetting, and review of the resulting proof before it is published in its final citable form. Please note that during the production process errors may be discovered which could affect the content, and all legal disclaimers that apply to the journal pertain. 
Results-A total of 460,611 patients were screened; 7,207 patients with dry eye were included, while 20,004 patients with anxiety and 30,100 patients with depression were included. The adjusted odds ratio for dry eye disease and anxiety was 2.8 (95\% CI 2.6-3.0). For dry eye disease and depression, the odds ratio was 2.9 (95\% CI 2.7-3.1).

Conclusions-We identified a statistically significant association between dry eye disease and each of depression and anxiety. Such an association has implications for ophthalmologists in the management and treatment of dry eye disease.

\section{Introduction}

Dry eye disease is a multifactorial chronic disease with variable prevalence. The International Dry Eye Workshop (DEWS) researchers have discussed extensively the inherent difficulty in defining its prevalence and demography. ${ }^{1}$ Dry eye disease remains a largely symptomatic diagnosis, without a single defining diagnostic test. ${ }^{1}$ Despite these difficulties, several population-based studies have reported the prevalence of dry eye, with quoted prevalence rates ranging from $5.5 \%$ to $33.7 \%$. Other researchers argue that the true prevalence is considerably higher. ${ }^{2-12}$ Nevertheless, there is little question that dry eye remains a common and complex problem for health care providers. In addition, dry eye is associated with other ocular and systemic illnesses. Sjogren's syndrome, for example, is an autoimmune disease, which has as part of its diagnostic criteria the presence of dry eye. Rheumatoid Arthritis and dry eye are related to each other as well. ${ }^{13,14}$ Studies have found an association between dry eye and diabetes mellitus ${ }^{1,15}$ though other studies have not shown this link. ${ }^{16}$

More recently, several population-based studies have investigated a possible association between dry eye and depression. Wen et al (2012) observed an increased frequency of dry eye disease in 472 psychiatric patients being treated for a variety of psychiatric illnesses, including depression and anxiety. ${ }^{17}$ Likewise, Galor et al (2011) demonstrated an association between dry eye disease and post traumatic stress disorder as well as depression in a veterans population. ${ }^{18}$ Finally, a recent study from the Beijing Eye Study identified an association between dry eye disease and depression symptoms in an elderly population in Beijing. ${ }^{19}$ However, all current data available on this association has focused on a small population ${ }^{20}$ or in an age-specific population such as the elderly. ${ }^{19,21}$

The purpose of this study was to investigate the association between dry eye disease and both depression and anxiety in a large adult population in the United States. To our knowledge, this is the largest population in which these associations have been studied to date. In addition to depression, we analyzed the association between dry eye and another disease with an already known association, rheumatoid arthritis, to validate our analytical approach.

\section{Methods}

We performed a retrospective case-cohort study by performing a chart review using the Carolina Data Warehouse of all patients seen in the outpatient setting at the University of North Carolina between July of 2008 and June of 2013. The study design was prospectively 
approved by the University of North Carolina Institutional Review Board. The Carolina Data Warehouse is a repository of clinical, research, and administrative data captured from the electronic health records of all patients who have entered into the University of North Carolina Health Care System since July 1, 2004. Our study population included any patient over the age of 18 years old at the time of data extraction with any data in the Carolina Data Warehouse. Cases were defined according to ICD-9 codes as follows: Dry Eye Disease (ICD-9 code 375.15), Anxiety (ICD-9 code 300, 300.00, 300.01, 300.02), Depression (311, $296.2 \times, 296.3 \times$ ), or Rheumatoid Arthritis (ICD-9 code 714.0). Patients for whom age could not be determined were excluded.

Using the diagnostic codes outlined above, odds ratios were separately estimated between dry eye and each of the other diseases. We were primarily interested in the associations between the diagnosis of dry eye disease and each of depression and anxiety.

We used separate logistic regression models to estimate associational odds ratios, each adjusted for age group and gender, along with $95 \%$ confidence intervals. For purposes of deidentification, data were extracted from the Carolina Data Warehouse, and aggregated by gender and age group, with age groups pre-defined as 18 to 35 years, 36 to 50 years, 51 to 65 years, and older than 65 years. These age groups were defined prior to the data analysis. To explore the potential for differential associations across age groups, we fit additional models that included disease-by-age-group interactions. We report $95 \%$ confidence intervals for the associations within each of these age groups along with a test of the interaction term for comparing associations across age groups.

\section{Results}

A total of 460,611 patients were included in the analysis; the clinic payer mix was estimated to be $50 \%$ Medicare, $25 \%$ private insurance, $15 \%$ Medicaid, and $10 \%$ uninsured. Of the 460,611 patients, there were 7,207 patients with dry eye, 20,004 patients with anxiety and 30,100 patients with depression. Seventy-six patient records were excluded because age could not be determined. Table 1 summarizes the aggregated data. Table 2 presents the prevalence of dry eye in patients with each of depression and anxiety, respectively.

The estimated odds ratio between dry eye disease and anxiety was 2.8, with a $95 \%$ confidence interval of $(2.6,3.0)$ (See Table 3 ). The estimated odds ratio between dry eye disease and depression was 2.9 , with a $95 \%$ confidence interval of $(2.7,3.1)$. The estimated odds ratio between dry eye disease and rheumatoid arthritis was 3.2, with a 95\% confidence interval of $(2.8,3.7)$. We found evidence that these associations differed across age groups (Table 4). Notably, there was a greater association with Dry Eye and Rheumatoid Arthritis in the youngest age group compared to the older age groups.

\section{Discussion}

The purpose of this study was to analyze the association between dry eye disease and each of depression and anxiety. As discussed previously, other studies of these associations had focused on a specific population, such as an elderly population in Beijing or a veterans affairs population. ${ }^{17,18}$ Our study, however, included over 7,000 patients with dry eye across 
all age groups, which we argue represents a larger and more diverse population than previously studied.

We identified statistically significant associations between dry eye disease and each of depression and anxiety. Such an association is of importance to the eye care provider, who may serve as the entrance to medical care for patients. For example, in the case of diabetes mellitus, patients who have been previously undiagnosed with the disorder may present initially to the eye care provider due to a decrease in vision. Given our findings, we believe this may be the case for patients with depression and anxiety as well, who may present to seek medical care first with symptoms of dry eye. Perhaps there is a role for the eye care provider to initiate screening measures in dry eye patients for these comorbidities. To our knowledge, ours is the first study to discuss this as a possible role for the eye care provider.

Additionally, the association between dry eye and depression offers a potential therapeutic intervention target. The effects of adequate treatment of depression on successful therapy for other comorbid conditions has been demonstrated for other medical conditions such as chronic obstructive pulmonary disease ${ }^{22}$ and stroke. ${ }^{23}$ Perhaps the treatment of dry eye disease, then, would also benefit from treatment of depression and/or anxiety.

Psychiatric diseases such as depression and anxiety have been linked to a number of chronic medical conditions, including arthritis, cancer, lung disease, heart disease, and diabetes, among others. ${ }^{24-27}$ Some have argued that such associations should have implications for treatment of both the psychiatric disease as well as the chronic medical illness in the primary care setting. ${ }^{27}$ Given the nature of the association in our study, we offer that primary care providers should also view dry eye disease among the same group of chronic medical illnesses with implications for psychiatric disease. This recognition likewise should have screening and referral implications for primary care providers as well.

A major strength of this study is its size; to our knowledge, this is the largest population studied for such associations. The strength of our odds ratios reflects the size of the study and lends force to the associations demonstrated. A further strength lies in the inclusive nature of the study; unlike prior populations studied for an association between dry eye and depression, our population included all adult age groups and was not confined to a specific population, such as the veterans affairs population studied previously. ${ }^{18}$ As a result, the results of our study should be broadly generalizable.

Our study has limitations as well. Our population was entirely included from an academic medical center in North Carolina. However, we argue that our population is still more widely generalizable than other studies published on the same association. The clinic payer mix at our medical center reflects demographics which could be expected in a general ophthalmology clinic. In addition, we believe that the size and inclusivity of the population included in our study outweighs this limitation.

Another weakness of our study is its retrospective design, and as such causality cannot be determined by our analysis. Our primary research question was to assess the association of dry eye disease with depression or anxiety and the retrospective design was suited for this purpose. Furthermore, we argue that the therapeutic intervention advocated in our study 
does not depend on causality. Treatment of depression has been shown to improve control of other chronic medical conditions ${ }^{22,23}$. Therefore, from a clinical perspective, dry eye disease, anxiety, and/or depression require treatment. Adequate treatment requires that each disease be managed.

Additionally, our study was limited to those who presented for care, which demonstrates a possible area of confounding. However, the primary aim of our study was simply to investigate a possible association between dry eye and depression and anxiety. Furthermore, data were extracted only in the aggregate, which precluded both controlling for individuallevel characteristics other than gender and age as well as simultaneously modeling all disease-dry eye associations. As argued above, we feel that the strength of the association proven by our study outweighs this limitation.

An additional weakness of the study is possible confounding by the medications used to treat depression. Antidepressant use has been identified as a risk factor for dry eye. ${ }^{5,28,29}$ However, this association has been primarily linked to anticholinergic effects of such medications as tricyclic antidepressants. Expert consensus within the University of North Carolina Psychiatry Department is that the use of tricyclic antidepressants has decreased markedly in recent years. In contrast, selective serotonin reuptake inhibitors, the newest and now most often used class of antidepressant medications, are thought to have less anticholinergic activity, which suggests that their contribution to dry eye may be less. ${ }^{30}$

Similarly, we did not gather data regarding the level of treatment each patient had received for either dry eye or depression or anxiety. Our study was designed to assess a large and diverse population in order to definitively support the proven association. As such, it was not feasible to further distinguish where on the therapeutic spectrum each case occurred. However, as we describe previously, we argue that the size and generalizability of our population allows for the demonstration of a strong association, and that this outweighs this weakness.

Our study identified statistically significant associations between dry eye and the psychiatric diseases of depression and anxiety in a large population study. The nature of these associations, including causality as well as a possible link to antidepressant medications, warrant further study. Further study of these associations may also focus on the treatment of depression and anxiety and possible therapeutic effects on the management of dry eye, given similar results in the treatment of other medical diseases associated with these psychiatric conditions. The associations described in this study are applicable to clinical practice, with respect to eye care, primary care, and psychiatric care for patients with dry eye disease.

\section{Acknowledgments}

This research was supported by a grant from Research to Prevent Blindness, which was independent of study data reporting and interpretation. Dr. Robert van der Vaart contributed to conception and design, analysis and interpretation, writing of the article, critical revision of the article, final approval of the article, provision of materials, patients, or resources, and literature search. Dr. Chelsea Lefebvre contributed to conception and design, analysis and interpretation, critical revision of the article, final approval of the article, and provision of materials, patients, or resources. Mark Weaver contributed to analysis and interpretation, critical revision of the article, final approval of the article, and statistical expertise. Dr. Richard Davis had full access to all of the data in the study and 
takes responsibility for the integrity of the data and the accuracy of the data analysis, and contributed to every aspect of the manuscript.

\section{References}

1. DEWS Epidemiology Subcommittee. The Epidemiology of Dry Eye Disease: Report of the Epidemiology Subcommittee of the International Dry Eye Workshop. The Ocular Surface. 2007; 5(2):93-107. [PubMed: 17508117]

2. Schein OD, Hochberg MC, Munoz B, et al. Dry Eye and dry mouth in the elderly: a populationbased assessment. Arch Intern Med. 1999; 159(12):1359-1363. [PubMed: 10386512]

3. Schein OD, Munoz B, Tielsch JM, Bandeen-Roche K, West S. Prevalence of Dry Eye among the elderly. Am J Ophthalmol. 1997; 124(6):723-728. [PubMed: 9402817]

4. Munoz B, West SK, Rubin GS, et al. Causes of blindness and visual impairment in a population of older Americans: The Salisbury Eye Evaluation Study. Arch Ophthalmol. 2000; 118(6):819-825. [PubMed: 10865321]

5. Moss SE, Klein R, Klein BE. Prevalence and risk factors for dry eye syndrome. Arch Ophthalmol. 2000; 118(9):1264-1268. [PubMed: 10980773]

6. Schaumberg DA, Sullivan DA, Buring JE, Dana MR. Prevalence of dry eye syndrome among US women. Am J Ophthalmol. 2003; 136(2):318-326. [PubMed: 12888056]

7. Christen WG, Manson JE, Glynn RJ, et al. Low-dose aspirin and risk of cataracts and subtypes in a randomized trial of US physicians. Ophthalmic Epidemiol. 1998; 5(3):133-142. [PubMed: 9805346]

8. Christen WG, Gaziano JM, Hennekens CH. Design of Physicians' Health Study II- a randomized trial of beta carotene, vitamins $\mathrm{E}$ and $\mathrm{C}$, multivitamins, in prevention of cancer, cardiovascular disease and eye disease, and review of results of completed trials. Ann Epidemiol. 2000; 10(2):125134. [PubMed: 10691066]

9. Chia EM, Mitchell P, Rochtchina E, Lee AJ, Maroun R, Wang JJ. Prevalence and associations of dry eye syndrome in an older population: the Blue Mountains Eye Study. Clin Experiment Ophthalmol. 2003; 31(3):229-232. [PubMed: 12786773]

10. McCarty CA, Bansal AK, Livingston PM, Stanislavsky YL, Taylor HR. The epidemiology of dry eye in Melbourne, Australia. Ophthalmology. 1998; 105(6):1114-1119. [PubMed: 9627665]

11. Lin PY, Tsai SY, Cheng CY, Liu JH, Chout P, Hsu WM. Prevalence of dry eye among an elderly Chinese population in Taiwan: the Shihpai Eye Study. Ophthalmology. 2003; 110(6):1096-1101. [PubMed: 12799232]

12. Lee AJ, Lee J, Saw SM, et al. Prevalence and risk factors associated dry eye symptoms: a population based study in Indonesia. Br J Ophthalmol. 2002; 86(12):1347-1351. [PubMed: 12446361]

13. Lemp MA. Dry Eye (Keratoconjunctivitis Sicca), rheumatoid arthritis, and Sjogren's syndrome. Am J Ophthalmol. 2005 Nov; 140(5):898-899. [PubMed: 16310468]

14. Fujita M, Igarashi T, Kurai T, Sakane M, Yoshino S, Takahaski H. Correlation between dry eye and rheumatoid arthritis activity. Am J Ophthalmol. 2005 Nov; 140(5):808-813. [PubMed: 16289424]

15. Wang TJ, Wang IJ, Hu CC, Lin HC. Comorbidities of dry eye disease: a nationwide populationbased study. Acta Ophthalmol. 2012; 90(7):663-668. [PubMed: 20809911]

16. Chiang PP, Lamourex EL, Zheng Y, et al. Frequency and risk factors of non-retinopathy ocular conditions in people with diabetes: the Singapore Malay Eye Study. Diabet Med. 2013; 30(2):e32e40. [PubMed: 23074990]

17. Wen W, Wu Y, Chen Y, et al. Dry Eye Disease in Patients with Depressive and Anxiety Disorders in Shanghai. Cornea. 2012; 31(6):686-692. [PubMed: 22382595]

18. Galor A, Feuer W, Lee DJ, et al. Prevalence and Risk Factors of Dry Eye Syndrome in a United States Veterans Affairs Population. Am J Ophthalmol. 2011; 152(3):377-384. [PubMed: 21684522] 
19. Labbe A, Wang YX, Jie Y, Baudouin C, Jonas JB, Xu L. Dry eye disease, dry eye symptoms and depression: The Beijing Eye Study. Br J Ophthalmol. 2013 Nov; 97(11):1399-1403. [PubMed: 24013959]

20. Li M, Gong L, Sun X, Chapin WJ. Anxiety and depression in patients with dry eye syndrome. Curr Eye Res. 2011 Jan; 36(1):1-7. [PubMed: 21174591]

21. Kim KW, Han SB, Han ER, et al. Association between Depression and Dry Eye Disease in an Elderly Population. Investigative Ophthalmology and Visual Science. 2011 Oct; 52(11):79547958. [PubMed: 21896858]

22. Fritzsche A, Clamor A, von Leupoldt. Effects of medical and psychological treatment of depression in patients with COPD- a review. Respiratory Medicine. 2011; 105(10):1422-1433. [PubMed: 21680167]

23. Donnellan C, Hickey A, Hevey D, et al. Effect of mood symptoms on recovery one year after stroke. Int J Geriatr Psychiatry. 2010; 25(12):1288-1295. [PubMed: 21086539]

24. Wells KB, Golding JM, Burnam MA. Psychiatric disorder in a sample of the general population with and without chronic medical conditions. Am J Psychiatry. 1988; 145(8):976-981. [PubMed: 2969199]

25. Roy-Byrne PP, Davidson KW, Kessler RC, et al. Anxiety disorders and comorbid medical illness. Gen Hosp Psychiatry. 2008; 30(3):208-225. [PubMed: 18433653]

26. Ali S, Stone MA, Peters JL, Davies MJ, Khunti K. The prevalence of comorbid depression in adults with Type 2 diabetes: a systematic review and meta-analysis. Diabet Med. 2006; 23(11): 1165-1173. [PubMed: 17054590]

27. Katon WJ. Epidemiology and treatment of depression in patients with chronic medical illness. Dialogues Clin Neurosci. 2011; 13(1):7-23. [PubMed: 21485743]

28. Jeppesen KV, Fledelius HC. Femoxetine and Eye Function: A Study of Possible Anticholinergic Side Effects. Pharmacopsychiatry. 1985; 18(3):231-234. [PubMed: 4011671]

29. Wong J, Lan W, Ming Ong L, Tong L. Non-hormonal systemic medications and Dry Eye. The Ocular Surface. 2011; 9(4):212-226. [PubMed: 22023816]

30. Celik L, Kaynak T, Ozerdem A, Kocak N, Kaynak S. Disappointment of patients on antidepressant therapy after excimer laser treatment. J Cataract Refract Surg. 2006; 32(10):1775-1776. [PubMed: 17010886] 


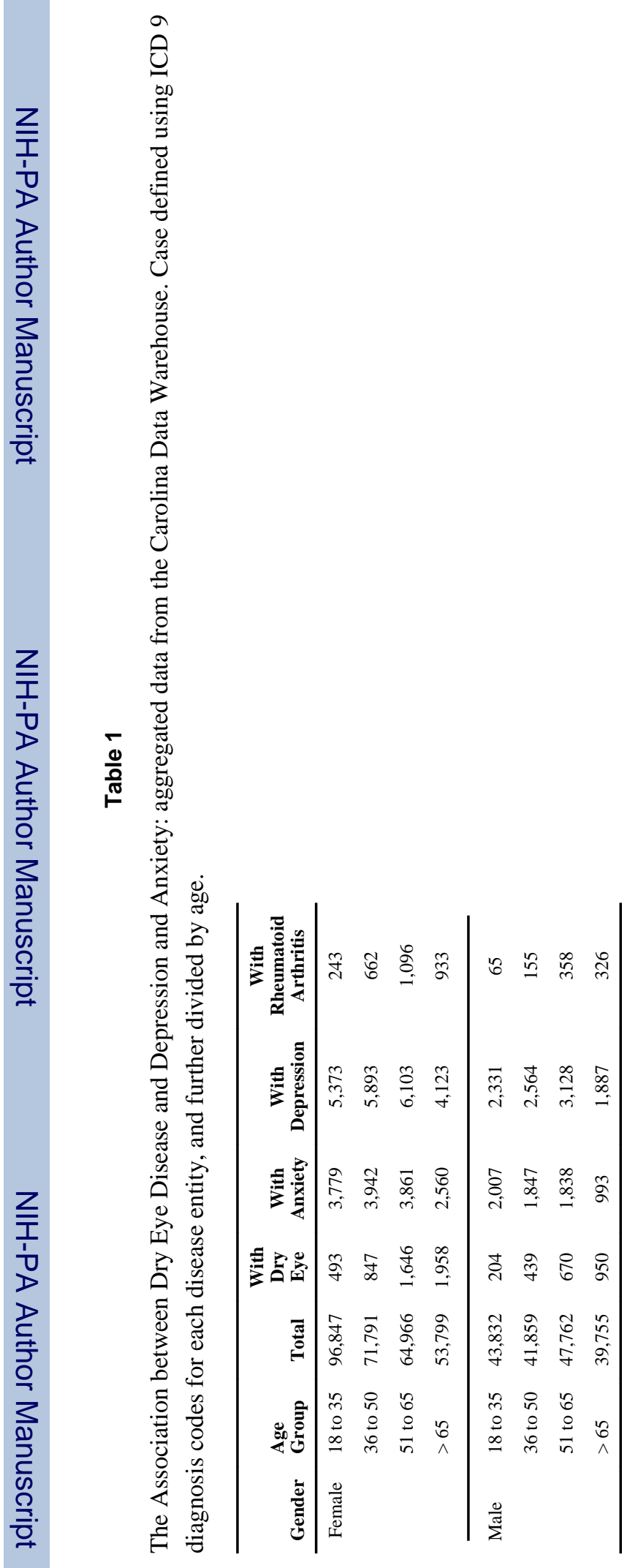




\section{Table 2}

Estimated prevalence of dry eye in patients with or without each of depression and anxiety.

\begin{tabular}{lccc}
\hline & With Dry Eye & Without Dry Eye & Total \\
\hline With Anxiety & $823(4.0 \%)$ & $20,004(96.0 \%)$ & 20,827 \\
Without Anxiety & $6,384(1.5 \%)$ & $433,400(98.5 \%)$ & 439,784 \\
\hline With Depression & $1,302(4.2 \%)$ & $30,100(95.8 \%)$ & 31,402 \\
Without Depression & $5,905(1.4 \%)$ & $423,304(98.6 \%)$ & 429,209 \\
\hline Total & 7,207 & 453,404 & 460,611 \\
\hline
\end{tabular}


Table 3

Estimated odds ratios between dry eye disease and each of depression, anxiety and rheumatoid arthritis

\begin{tabular}{lcc}
\hline Disease & $\begin{array}{c}\text { Adjusted Odds } \\
\text { Ratio }^{*}\end{array}$ & $\begin{array}{c}\text { 95\% Confidence } \\
\text { Interval }\end{array}$ \\
\hline Anxiety & 2.8 & $(2.6,3.0)$ \\
Depression & 2.9 & $(2.7,3.1)$ \\
Rheumatoid Arthritis & 3.2 & $(2.8,3.7)$ \\
\hline
\end{tabular}

* Adjusted for patient gender and age group 
Table 4

Estimated odds ratios between dry eye disease and each of depression, anxiety and rheumatoid arthritis, by age group.

\begin{tabular}{|c|c|c|c|}
\hline $\begin{array}{l}\text { Disease } \\
\text { Age group }\end{array}$ & Adjusted Odds Ratio* & $\begin{array}{l}\text { 95\% Confidence } \\
\text { Interval }\end{array}$ & P-Value ${ }^{t}$ \\
\hline Anxiety & & & 0.001 \\
\hline 18 to 35 & 2.4 & $(1.8,3.1)$ & \\
\hline 36 to 50 & 2.0 & $(1.7,2.4)$ & \\
\hline 51 to 65 & 3.0 & $(2.6,3.4)$ & \\
\hline$>65$ & 3.1 & $(2.7,3.5)$ & \\
\hline Depression & & & 0.004 \\
\hline 18 to 35 & 2.1 & $(1.7,2.7)$ & \\
\hline 36 to 50 & 2.5 & $(2.2,2.9)$ & \\
\hline 51 to 65 & 3.1 & $(2.8,3.5)$ & \\
\hline$>65$ & 3.1 & $(2.8,3.4)$ & \\
\hline Rheumatoid Arthritis & & & 0.003 \\
\hline 18 to 35 & 6.8 & $(3.6,12.8)$ & \\
\hline 36 to 50 & 3.7 & $(2.6,5.2)$ & \\
\hline 51 to 65 & 3.8 & $(3.1,4.6)$ & \\
\hline$>65$ & 2.5 & $(2.0,3.1)$ & \\
\hline
\end{tabular}

* Adjusted for patient gender.

${ }^{\dagger} \mathrm{P}$-value from test of interaction between disease and age group. 